\title{
Leading in a global context: The balancing act between leadership and management
}

\author{
Nafiisa Sobratee \\ Shamim Bodhanya \\ Graduate School of Business and Leadership \\ University of KwaZulu Natal, Durban, South Africa
}

\author{
Keywords \\ Complex organisations, leadership vs management, global forces, competing tensions
}

\begin{abstract}
Global mega-trends are leading to increasing levels of complexity, dynamism andturbulence within organisations. In an uncertain economy, organisations need real strategies that will enable them to thrive. Traditional leadership approaches have been rendered insufficient by rapid changes in the knowledge economy. The leadership literature has typically conceptualised the construct in terms of leader style and behaviour and, leader-follower relations. But findings from this stream are far from convergent and cogent. The purpose of this article is to create a theory-based integrative framework that can be used to identify the components comprising management and leadership. It re-examines the link among the self, others and the organisation and, how leadership should be conceptualised in the increasingly global contemporary context. Specifically, we apply the dichotomy of management versus leadership to theorise that it is not simply a matter of individual differences in competencies, skills and attitudes that ensure the development of creative and talented leaders. Rather, it is about how praxis, practice and the practioner offer both a challenge and transformation lens to observe the ways that global leadership is bounded and constrained by organisational and managerial conventions. In essence, this work suggest that leaders and managers need to apply systemic thinking competencies to catalyse organisational performance in the current fast-changing, knowledge-driven global business landscape in order to remain competitive.
\end{abstract}

Corresponding author: Nafiisa Sobratee

Email addresses for corresponding author: nsobratee@yahoo.com

First submission received: $21^{\text {st }}$ September 2017

Revised submission received: $15^{\text {th }}$ November 2017

Accepted: 22nd December 2017

Acknowledgement

The authors would like to thank the University of KwaZulu Natal for funding this publication.

\section{Introduction}

The challenges of globalisation, an accelerating pace of change, networked and dynamic organisations, and the demand for ethical and accountable leadership extend to all organisations. Literature has systematically shown that there are a few recurrent assumptions about what would constitute future leadership challenges across all sectors (Hagen, Vaicys \& Hassan, 2011; Mobley \& Dorfmann, 2003; Morse, 2007). Firstly, it acknowledges the huge impact of technology advancement on societies, businesses, and governments. Second, global trends that include free-trade initiatives and demographic shifts have led to greater competition and regional conflict. Third, there, are more than ever before, marked changes in the global talent pool that vary by region but include an aging workforce in developed countries and, social and political disorders from inequities in developing countries. Finally, these growing interconnectedness require constant agile mind-set (Dunn, Lafferty \& Alford, 2012). This implies that we are in an era of accelerating change that places new demands on leaders at all levels. These demands require leaders and organisations that adapt quickly to unforeseen contingencies. In a provocative article titled "Leadership: Who Needs It?", Gronn (2003) outlines a series of issues with conventional leadership assumptions including the relationship between leadership and management, the connection between leadership and power, the leader-follower "binary," and the cult of the leader's 
"exceptionality." He concludes that "if leadership is to retain its conceptual and practical utility, then it has to be reconstituted..."

Undeniably, since the last two decades, the way we understand the leadership phenomena has evolved disruptively. Traditional management methods seem no longer sufficient to address the volume of change we are witnessing. Business is not running as usual. Leaders must deal with growing volatility, uncertainty, complexity, and ambiguity in their decision-making environments. Consequently, scholarly research on the topic of leadership has witnessed a dramatic increase over the last decade, resulting in the development of diverse leadership theories. The field has advanced from theory that focuses on understanding general leadership processes as they occur over indeterminate amounts of time to a phenomenon that evolves over different time spans depending on the hierarchical level at which leaders are investigated (Kaiser, Hogan, \& Craig, 2008). Some authors have developed theories to advance knowledge about how micro processes, such as perceptions, emotions, and cognitions (Bono \& Ilies, 2006; Dinh \& Lord, 2012), and macro processes, such as the social-relational context (DeRue \& Ashford, 2010), dynamically affect follower and leader outcomes. Other scholars have explained a leader's role within complex systems for instigating organisational change and managing dynamic social networks (Balkundi, Kilduff, \& Harrison, 2011; Hannah, Lord, \& Pearce, 2011; Marion \& Uhl-Bien, 2002; Uhl-Bien \& Marion, 2009).

This article begins by presenting some organisational concepts that would enable leaders to frame an understanding of the leadership challenges in the context of Volatility, Uncertainty, Complexity and Ambiguity (VUCA) situations. A theory-based integrative framework is then presented to showcase the components that depict the balancing act between management and leadership in a three-tier process which consist of the self (the leader), others (people management challenges) and the organisation which is characterised by competing tensions embedded within multi-focal complexities. Finally, a concise discussion analyses the local and global imperatives which require that leaders frame and develop talent in order to 'crack' the potential in people, communities and organisations to succeed in VUCA environments.

\section{How do organisations respond to a global disruptions?}

Murthy \& Murthy (2014) posited a hierarchical classification of enactments, practices and virtues that comprise an emerging adaptive leadership response to the prevailing volatile, uncertain, complex and ambiguous (VUCA) conditions. The term 'VUCA' was coined by the US Army War College to describe the dynamic nature of the post-cold war era, which has since then, also caught on in a variety of organisational settings to describe a business environment characterised by (i) volatility - the nature, speed, volume, magnitude and dynamics of change, (ii) uncertainty - the lack of predictability of issues and events, (iii) complexity - the confounding issues and chaos that surround any organisation and (iv) ambiguity - the haziness of reality and the mixed meanings of conditions (Horney, Pasmore \& O'Shea, 2010). Organisations cannot control the direction that powerful global forces namely, a) advances in science and technology, b) global redistribution of knowledge, power, and wealth, c) competing political, cultural, and religious ideologies, and d) sustainability of the physical environment will take over the next 50 years (Latham, 2014). But they can control how they respond to these forces. In fact, we consider that harnessing a multi-focal approach within an organisation and transforming it into a more predictable resource is the single biggest factor in converting its challenges into distinct competitive advantage. There are a number of concepts that would help to comprehend how leaders should constantly frame and reframe organisational challenges under VUCA conditions.

\section{Complexity and uncertainty}

Complexity science has greatly contributed to creating new organisational metaphors and new perspectives about leadership.Complexity does not simply mean "many moving parts." Derived from the Latin root meaning"to entwine," it refers to the dynamic behaviour of systems whose parts continually interact and reorganise themselves into more adaptive patterns over time (Pascale, Millemann \& Gioja, 2000). It is "a systemic state on the cusp between chaos and order, a condition where uncertainty, variety, dependency, and interconnectedness are high" (Falconer, 2002) and as Kauffmann \& Macready (1995) put it "a grand compromise between structure and surprise". Eisenhardt \& Bhatia (2002) mention that the 
most significant value of complexity theory within organisational thinking is in providing an explanation of how organisations adapt and grow, especially in high-velocity environments where pace, ambiguity and uncertainty reign.

\section{Entrepreneurial mindset}

Both strategic management and entrepreneurship are concerned with decisions made by general managers who have responsibility for a total business (Ireland et al., 2001). In fact, Drucker (1999) argue, business - and every other organisation today - has to be designed for change as the norm and, to create change rather than react to it. An organisation that does not innovate and does not engage in entrepreneurship will not survive long. Management and entrepreneurship are only two different dimensions of the same task (Lumpkin \& Dess, 1996). However, an entrepreneur who does not learn how to manage will not last long. Similarly, a management that does not learn to innovate will not last long.But entrepreneurial activities do not fit within the traditional assumptions of management's domain - which explains why they have come so commonly to be regarded as different, if not incompatible. This is because strategic management has placed great emphasis on examining influences on firm performance, including strategy and environment, and the sources of sustainable competitive advantage. Entrepreneurship, both in considering independent firms and corporate entrepreneurship, has, in contrast, emphasised processes which lead to venture creation (Hoskinson et al., 2011). Independently, the actions involved with entrepreneurship and strategic management processes contribute to firm growth and success. When integrated, however, these actions create synergy that enhances the value of their outcomes (Dess \& Lumpkin, 2005).

\section{Contextual responsiveness}

Researchers have indicated that there is a close relationship between organisational context and leadership. Transformational leaders create a dynamic organisational vision that often necessitates a metamorphosis in cultural values to reflect greater innovation (Lord et al., 2001; Bredeson, Klar \& Johanson, 2011). Contextual factors have significant influence on the emergence, operation, and effectiveness of transformational leadership (Avolio \& Bass, 1988; Bryman, 1992; Pettigrew, 1987). Pawar and Estman (1997) specify how organisational contexts with differing levels of receptivity to transformational leadership require different transformational processes. The term 'receptivity' here refers to organisational members' responsiveness to the transformational leader's vision and attempts to align organisational members' self-interests with collective interests. Similarly, Shamir \& Howell (1999) argue that the emergence and effectiveness of leadership may be facilitated or inhibited by the organisational environment and life-cycle stage with the addition of further factors external to the organisation such as: technology, tasks, goals, structure, and culture, as well as the leader's level in the organisation and the circumstances surrounding his or her appointment.

\section{Strategic robustness}

Strategy is a set of integrated choices that a company makes to position itself in its respective industry, thereby creating a sustainable competitive advantage (Hill, Jones \& Schilling, 2014). These choices are backed by a set of activities or competencies that a firm builds and takes to the market, which are unique and cannot be easily replicated by competitors. While these are the basic principles of an acceptable strategy, the point that is given least attention by executives is how to integrate this strategy with all the company's stakeholders and make it more compelling and exciting for them. Managers are the linchpins in the strategy-making process. Individual managers must take responsibility for formulating strategies to attain a competitive advantage and for putting those strategies into effect (Kaplan \& Norton, 2001). They must lead the strategy-making process.

Moreover, a robust strategy not only focuses on external business market, but also simultaneously builds an internal culture by both communicating the strategy effectively across the company and making it more exciting and compelling for its stakeholders to follow and execute (Carpenter, 2002). The power of the robust strategy leads to the leadership commitment, alignment of the actions to the strategy and, increase the capabilities and competencies to beat the competitors and win over the clients in order to make profit. 
Formal strategic planning models stress that an organisation's strategy is the outcome of a rational planning process. The major components of the process are defining the mission, vision, values, and major goals of the organisation; analysing the external and internal environments of the organisation; choosing a business model and strategies that align an organisation's strengths and weaknesses with external environmental opportunities and threats; and adopting organisational structures and control systems to implement the organisation's chosen strategies. However, strategy can also emerge from deep within an organisation in the absence of formal plans as lower-level managers respond to unpredicted situations (Bodwell \& Chermack, 2010; Kopmann et al., 2017; Mintzberg \& Waters, 1985; Mirabeau \& Macguire, 2014).

\section{Managing complexity and uncertainty}

The leadership models many organisations have used in the past no longer seem adequate for effectiveness and success in the 21st-century organisational environment (Sacks, 2017). The situation in their sector has changed from when the environment and processes were stable or slow. In many sectors, work processes are changing at a much faster pace as organisations face the challenges of rapidly changing technology, globalisation, unpredictability, and turbulence. In the past, because of monopoly to technology, market, or brand, they could expect to be successful for a long-time despite the inability or refusal to innovate. However, due to the volatile environment in these sectors, many such organisations are failing and need creativity and constant innovation to remain competitive and successful (Cohen, 2001). This means that they must recognise and harness the creativity and leadership that exist in the organisation to manage its innovation processes. Strategic design, technology, culture, and organisational strategy may not be able to sustain them very long unless organisations also establish a structure that continuously develops creative leaders to run and sustain the process (Andriopoulos \& Lowe, 2000; Zhang \& Zhou, 2014). This strategy will help the organisations establish environments that are conducive to renewal, build organisational culture that encourages innovations, and establish organisational diversity that in turn sustain competitiveness.

\section{Creative self-programmable professionals}

Contemporary "knowledge economies" are seeing the emergence of new paradigms for innovation and the advancement of knowledge in relation to economic production (Bond \& O'Byrne, 2014). Knowledge or innovation are not new ingredients of economic growth. Rather, against a background of a rapid acceleration in the development of knowledge, a revolution in the instruments of knowledge and a necessary redefinition of some of the components of knowledge, the drivers of knowledge advancement are also inevitably changing. For instance, the process of inventing, developing and bringing to users a $21^{\text {st }}$ century microelectronic product is very different from the equivalent process in the case of, say, the light-bulb in the 19th century. What, then, are the newly emerging patterns of education, curriculum development and life-long learning under such turbulent knowledge needs? Some researchers developed the concept of 'productive pedagogies', a model of pedagogy that is deemed to be socially just and appropriate for the contemporary post-modern globalised world (Lingard et al., 2001, 2003; Hayes et al., 2005). The model also sits as a counter to the inauthentic post-modernist model of pedagogy framed by neo-liberal and new public management forms of accountability in some educational systems (Ball, 1999, 2004). Another author, Rose (1999), adumbrates the institutional, individual, space and time effects contingent upon the development of this newly emerging entrepreneurial self in his 'Powers of Freedom: reframing political thought':

"Education is no longer confined to 'schooling', with its specialised institutional sites and discrete biographical locus. The disciplinary individualisation and normalisation of the school sought to install, once and for all, the capacities and competencies for social citizenship. But a new set of educational obligations are (sic) emerging that are not confined to space and time in the same ways. The new citizen is required to engage in a ceaseless work of training and retraining, skilling and reskilling, enhancement of credentials and preparation for a life of incessant job seeking: life is to become a continuous economic capitalisation of the self." (Rose, 1999, pp. 160-161) 
Many industries are now so competitive that companies must adopt a transnational strategy. This involves a simultaneous focus on reducing costs, transferring skills and products, and being locally responsive. Implementing such a strategy may not be easy. In a network society characterised by fluidity, key competence for social actors in this ever changing technology-permeated environment is the ability to cope with change - described through Castells' conceptualisation self-programming (Levinsen, 2011). Castells' theory has influenced international definitions of future key competencies. Self-programming ability is thus a sustainable competence for the contemporary organisation and its future.

\section{The Self}

Leadership is authentic influence that creates value (Rego et al., 2014). From this perspective, leadership is not viewed as hierarchical; it exists everywhere in organisations. Three essential questions emerge to enhance our understanding of leadership effectiveness. How can we enhance our authenticity as a leader? How can we extend the influence we have? How can we create more value? A manager's ability to make difficult decisions effectively is most influenced by organisational context, leadership, or their own personal values (Fairholm, 2000). There is, therefore, a difference between management and leadership (Kotter, 2008). Management is about coping with complexity. Its practices and procedures are largely a response to one of the most significant contemporary developments: large and decentralised organisations. Good management brings a degree of order and consistency to key dimensions like the quality and reliability of services. Leadership, in contrast, is about enacting values and culture to cope with change and to make the decision to change.

In effect, successful leaders working under VUCA context tend to exhibit seven principle characteristics: integrity, competence, vision, commitment, affinity, duty, and accountability (Springer, 2007). The organisational shift to values-based measurement occurs most often when leaders in the organisation, both at the top and at the bottom, agree upon values, set standards, and operationalise them using open communication. Leaders are seen as critical to this process because they are capable of first making a decision that needs to be made, articulating why the decision has been made, identifying and overcoming barriers to moving ahead, gaining commitment, and taking responsibility for guiding the process.

In fact, these abilities are attributes of the concept of self-efficacy and is an important component for understanding the guiding principles of transformational leadership (Fitzgerald \& Schutte, 2010.). According to Bandura (1977) and Gist \& Mitchell (1992), self-efficacy is an estimate of a leader's ability to orchestrate performance through successfully executing the behaviors that are required to produce desired outcomes. Paglis \& Green (2002), in a study that assessed managers' motivation for attempting the leadership of change, established that several positive relationships were between three leadership selfefficacy dimensions namely, (i) direction setting, (ii) gaining commitment, (iii) overcoming obstacles and self-esteem, subordinates' performance abilities, and managers' job autonomy. Self-leaders play a critical role in enabling and supporting the awakening and fostering of creativity and innovation - the basis of a newly emerging leadership type, that of authenticity (Avolio \& Gardner, 2005; Arda, Aslan \& Alpkan, 2016).

According to Goleman (2011), leaders who possess a high degree of emotional intelligence tend to be more effective - their self-awareness and self-regulation help to elicit the trust and confidence of subordinates. Such individuals tend to be more self-confident and therefore, better able to cope with ambiguity and are highly motivated to deal with change. It is from this perspective that personal mastery, seen as the foundation for achievement in any endeavour, has started to receive attention in the management literature for its importance in the development of leadership (Dhiman, 2017). It is not a simplistic process of merely affirming one's strengths while ignoring the weaknesses. Peter Senge (2006), in The Fifth Discipline, wrote, "people with a high level of personal mastery are acutely aware of their ignorance, their incompetence, their growth areas, and they are deeply self-confident. Paradoxical? Only for those who do not see the journey is the reward." A strong motivation exhibited in a passion for work can also be contagious, helping to persuade others to join together in pursuit of a common goal or organisational mission (Müceldili, Turan \& Erdil, 2013). 


\section{Others}

Natural science deals with the behaviour of objects. The reality of a natural science, the physical universe and its laws, do not change; or if they do, only over eons rather than over centuries, let alone over decades. But a social discipline such as management deals with the behaviour of people and human institutions. It is thus subject to continuous change in the wake of increasing people management challenges. This means that assumptions that were valid yesterday can become invalid and, indeed, totally misleading in no time at all. The new assumption on which management, both as a discipline and as a practice, is increasingly basing itself is that the scope of management is not legal, that is, it does not involve only command and control. Instead, it has to be operational, embrace the entire process, be focused on results and performance across the entire economic chain.

\subsection{Task vs relational}

With increasing project requirements, however measured (complexity, project type, duration, etc.), there is an increasing need for emotional competencies in the manager. Thus transactional leadership, and concern for process which falls under the management science perspective, is more important on relatively simple projects.

However, transformational leadership, and concern for people, is necessary on more-demanding projects. Research on leadership is clear: leaders must move from task-specific expertise to personal, interpersonal, and strategic excellence to succeed (Hollenbeck \& McCall, 1999). This represents a crucial leadership transition warranting the redefinition the task altogether to highlight the notion of "managing for performance" (Ruth, 2006). Early leadership theories started from a focus on the individual leader and his or her traits. Subsequently, leadership theory developed, first by taking into account the context of the leadership situation and, secondly, by shifting focus from the observable behaviour of personal attributes to the intellectual exchange and interpersonal relationships. When it is required to move beyond their functional specialties and address strategic issues facing the overall business, many managers do not immediately grasp that this will involve relational not analytical tasks (Muller \& Turner, 2010). In this context, networking is simultaneously one of the most self-evident and the most dreaded developmental challenges that aspiring leaders must address (Hovik \& Hansen, 2015).

\subsection{Rigidity vs flexibility}

Maintaining strategic flexibility is one of the most important yet most difficult tasks of managers and organisations in a dynamic environment (Hagen, Tootoonchi \& Siddiqi, 2006). In a highly uncertain environment, firms need the capabilities to enact major strategic changes to resolve problems in a timely fashion. A company's realised strategy is the product of carefully planned strategies which are actually put into action (the company's deliberate strategies) and of any unplanned, or emergent, strategies (Mintzberg \& Waters, 1985). In Mintzberg's (2017) view, many planned strategies are not implemented because of unpredicted changes in the environment.

In contrast, emergent strategies are the unplanned responses to unforeseen circumstances. These arise from autonomous action by individual managers deep within the organisation, serendipitous discoveries or events, or an unplanned strategic shift by top-level managers in response to changed circumstances. They are not the product of formal top-down planning mechanisms. Strategic flexibility is thus the organisation's capability to identify major changes in the external environment, quickly commit resources to new courses of action in response to those changes, and recognise and act promptly when it is time to halt or reverse existing resource commitments (Dibrell, Craig \& Nebaum, 2014). It requires managers to acknowledge the importance feedback thinking mechanisms to find the right balance between committing the resources necessary to carry out a decision and avoiding investment of good money in bad projects (Shimizu \& Hitt, 2004).

\section{3 Low bandwidth on goals vs multi-purposeful}

The nature of work today for many information workers resembles what used to be exclusive to top-level managers (Mintzberg, 2017), i.e. characterised by fast-paced and varied activities, frequent fragmentation of actions and constant interpersonal interactions.

The need to multi-task seems to be increasingly the norm as companies increasingly experience a flattening of organisational hierarchies, adopt team-oriented forms of organisation, 
constantly change organisational structures, relax the formalisation of job roles, and demand employees to focus on multiple and varied initiatives (DiMaggio, 2001; Cumming, 2016). In fields as diverse as finance, software development, consulting, and academia, it has become increasingly commonplace that information workers are involved in multiple collaborations.

Buscher et al. (1999) highlighted the lack of evidence that could explain strategies used by people who are involved in multiple and simultaneous projects in coping with the demands of multiple collaborations and activities. It is often said that multi-tasking involves the management of a set of diverse aspects such as time, contacts, documents or even physical space (Boardman \& Sasse, 2004). However, it is still not clear how, in practice, individuals can juggle priorities and what strategies they use to achieve this. Due to the accessibility of other co-workers, people often find themselves engaged in informal interactions thematically unrelated with the activity they were working on before an interruption. It is recognised that collaborative work demands these kinds of interactions as they serve both social and work oriented functions, and fundamentally, they serve as flexible mechanisms to cope with changing circumstances and problem-solving (Wellmann et al., 1996; Poocharoaen \& Ting, 2015). Therefore, given the perspective that people must manage multiple activities, organisational collaboration is not as an isolated experience in a particular context. Rather, it is multi-purposeful, consisting of an ongoing stream of activities where people move in and out of different collaborative contexts based on circumstances (Cumming, 2016).

\section{The organisation}

Globalisation, requirement for social responsibility, innovative technology and new strategic thinking are just a few of the aspects required in nowadays competitive economy. What is the difference between management and leadership? While management is the allocation of scarce resources against an organisation's objective, the setting of priorities, the design of work and the achievement of results, leadership in contrast focuses on the creation of a common vision (Weathersby, 1999). More specifically, leadership aims at motivating people to contribute to the vision and encouraging them to align their selfinterest with that of the organisation. Thus, management is about controlling while leadership involves persuasion (Figure 1).

\subsection{The machine vs living system metaphor}

Eisenhardt \& Bhatia (2002) explained that the most significant value of the complexity theory within organisational thinking is in providing an understanding of how organisations adapt and grow, "especially in high-velocity environments where pace, ambiguity and uncertainty reign". Among the valuable contributions of the complexity theory to management is the organisational metaphor of the living system to replace that of the dominant machine metaphor. These two radically different paradigms are contrasted by Knowles (2002) as shown in Table 1. They differ dramatically in terms of the extent to which the system accepts information from the outside and the way in which boundaries are defined. This paradigmatic shift has had profound implications for leaderhsip theory and practice.

\subsection{Bureaucracy vs adhocracy}

In the bureaucratic structural form, standardisation of work processes and tasks is used to coordinate the functioning of individuals. Different organisations build differing value systems into these transactions to strengthen individual self-interests to different degrees (Wilkins \& Ouchi, 1983). Bureaucracy is used to address the dual social problems of ensuring equity among organisational members while restraining and moderating their self-interests. The organisation and its employees make a partly specified contract, wherein the employees accept organisational authority in exchange for wages. Individual self-interests are restrained by monitoring employees compliance with transactional requirements (Wilkins \& Ouchi, 1983). Under this mode of governance, organisations do not temper members' self-interests through socialisation; rather, they curb self-interests through formalised monitoring and exchange mechanisms.

Mintzberg (1979) noted that in this structural form, top management's focus is on resolving the conflict induced by strict departmental differentiation, task fragmentation, and poor correspondence between social and technical systems. Top managers are also overburdened with operational decisions that come up the hierarchy, and they are preoccupied with a control mentality (Mintzberg, 1979). At the 
same time, the middle and lower level managers are fixated with the operational directives provided by top management. Thus, the top management's ability to develop a vision or mission is constrained, and middle management is concerned with the implementation of the operational directives.

In contrast, adhocracy, facilitate innovation (Mintzberg \& McHugh, 1985) and is likely to be receptive to organisational change through the development of vision. The vision evolves from the professionals who have knowledge, power, and a willingness to work collectively such that the commitment to the vision evolves through lateral processes (Daher, 2016; Petkova, 2014; Schatten et al., 2014)

Table 1. A comparison of organisational paradigms

The 'machine' metaphor
Knowledge is structured in pieces
Organisations are structured in functions
Work is structured as roles
People are narrowly skilled
Motivation is based on external forces
Change is a troubling exception
Information is shared on a 'need-to-know' basis
Information flows up and down the organisation
People work in prescribed roles
Information from the outside world is ignored
Organisational barriers inhibit cross-sectional interactions
People see only their part of the work

People see only their part of the work

\author{
The 'living system' metaphor \\ Knowledge is seamless \\ Organisations are a whole system \\ Work is flexible and without boundaries \\ People are multi-skilled and continuously learning \\ Motivation is based on links to the whole \\ Change is always present \\ Information flows freely and openly; people decide what they need \\ Information flows up, down, across and round the organisation \\ People work beyond their roles \\ Information from the outside world is valued and used \\ Interactions across roles and functions are extensive \\ People see their work in relation to the whole, knowing and doing \\ what needs to be done
}

Source: Knowles (2002)

\subsection{Efficiency vs effectiveness}

Bartuseviciene \& Sakalyte (2013) discuss organisational performance within entities effectiveness and efficiency perspective as these are common measures of the organisational performance. According to Mouzas (2006), each of these terms have their own distinct meaning. Most organisations assess their performance in terms of effectiveness where the main focus is to achieve their mission, goals and vision. At the same time, there is plethora of organisations, which value their performance in terms of their efficiency, which relates to the optimal use of resources to achieve the desired output (Chavan, 2009). The question is, whether there is a difference if the organisation is effective yet inefficient and vice versa. Also, what is the importance for the organisations to understand the disparity?

For the majority of the last century, the supremacy of the large corporation as the economic driver for national wealth led to the dominant theory of the firm being the resource-based view (RBV). This theory argues that the basis for any competitive advantage of a firm lies within valuable tangible and/or intangible resources that are at the firm's disposal (Wernerfelt, 1984). The distinction between tangible and intangible refers to resources, that is, goods (that are tradable and available to many firms) versus capabilities, which are more specific to a particular firm (Amit \& Schoemaker, 1993). Over time, the capabilities component has become the tentative basis of the knowledge-based view (KBV) of the firm. Knowledge-bases and the capability of their utilisation within an organisation affect overall organisational performance.

One the one hand, effectiveness is the level of results from the actions of employees and managers. Employees and managers who demonstrate effectiveness in the workplace help produce highquality results. It is the fit among the individual and strategy, structure, phase of organisational development, and situation that helps determine effectiveness (Boudreau, Ramstad \& Dowling, 2003; Sloan, Hazucha \& Van Katwyk, 2003). Companies measure effectiveness often by conducting performance reviews. In industry, the effectiveness of a workforce has an enormous impact on the quality of a company's product or service, which often dictates a company's reputation and customer satisfaction.

On the other hand, efficiency in the workplace is the time taken to complete a task. Efficient employees and managers complete tasks in the least amount of time possible with the least amount of resources possible by utilising certain time-saving strategies. Employees are often ineffective due to lack of overseeing and/or skills to contribute such that inefficiency result from poor dynamic capabilities for 
instance, the lack of knowledge about how to be efficient or the lack of necessary tools, techniques and technological adaptation to perform tasks efficiently (Ljungquist, 2014).

\subsection{Territorial orientation vs Entrepreneurial orientation}

Khandwalla's seminal work on contingency perspective (1972) shows that the performance of a company should not be measured in terms of one organisational attribute (strategy, structure, management style) as this would correspond to a territorial orientation standpoint. It was suggested that instead, a company's performance should result from the interplay of the strategy, structure and management style dimensions within a specific environment characterised by some degree of hostility, uncertainty and heterogeneity. The entrepreneurial orientation of an organisationis, therefore, described as a dimension of strategic posture represented by a firm's risk taking propensity, tendency to act in a competitively aggressive, proactive manner and reliance on frequent product innovation (Bamberet al., 2002). Organisations are said to have entrepreneurial orientation when a group of innovator organisational members are working together, producing fresh ideas and they are provided with a prevailing atmosphere conducive to acting on those ideas (Miles \& Arnold, 1991). Such an organisation concentrates on encouraging creative behaviouramong the employees and, thus, benefits by initiating development of new products, processesor systems to maintain and increase the presence in the market place. Creating an entrepreneurial orientation has turned out to be a more multi-faceted task for organisations than ever before.

\section{5 "Inside out" vs "outside in" or, outsight}

Ibarra (2015) coined a new term "outsight" to suggest that leaders should apply the concept of "outsight," or removing yourself from the day-to-day work routine and actively placing yourself in situations and scenarios in order to gather fresh perspectives, as well as new information on work, networks, and future potential. Such an approach may involve passing responsibilities on to subordinates in order to free up time for strategic thinking or meetings with peers inside and outside the organisation. The merit of the concept is that change comes from the 'outside in'; by acting differently and changing routines, a leader can achieve another level of innovation. Aristotle observed that people become virtuous by acting virtuous: if you do good, you'll be good. His insight has been confirmed in a wealth of social psychology research showing that people change their minds by first changing their behaviour, that is, change happens from the outside in, not from the inside out (Curzer, 2002).

Ibarra (2015) thus explains that the logical sequence-think, then act-is actually reversed in personal change processes such as those involved in becoming a better leader. Paradoxically, selfknowledge only increases in the process of making changes. She further explains that the principle holds that the only way to think like a leader is to first act: the leader plunges himself into new projects and activities, interact with very different kinds of people, and experiment with unfamiliar ways of getting things done.Those freshly challenging experiences and their outcomes will transform the habitual actions and thoughts that currently define a leader's limits. In times of transition and uncertainty, thinking and introspection should follow action and experimentation - not vice versa. A leader's true self, therefore, emerges as a result of the outcome his learning experience.

\subsection{Competing tensions}

Globalisation, requirement for social responsibility, innovative technology and new strategic thinking are just a few of the aspects required in nowadays competitive economy. Scholarly and practitioner evidence indicate that the subject has advanced dramatically in the last two decades as the world's market, politics and governance have become more volatile and uncertain, and organisations, complex and ambiguous (Hazy, 2006). Making sense of the leadership process is a constant challenge due to their messy nature. This is because such data constitute mainly of sequences of "events": conceptual entities that researchers are less familiar with. They often involve multiple levels and units of analysis whose boundaries are indefinite. Moreover, their temporal embeddedness often varies in terms of precision, duration, and relevance. Finally, despite the primary focus on events, the leadership process research tend to be eclectic, drawing in phenomena such as changing relationships, thoughts, feelings, and interpretations. It applies a multi-focal approach to shed light on contemporary leadership challenges. We consider that the onus is on the researchers and practitioners to develop sufficient consciousness to 
recognise the balancing act between leadership and management which is required to improve their insights on how to lead in a global context.

\section{Global forces vs local imperatives}

Global leadership is the ability to develop peak performance through the talents and potential of a diverse set of people, organisations, and societies. The dynamics, complexity and diversity, now characteristic of global environment, are diffusing into the domestic environment (Gregersen et al., 1998; Harvey \& Buckley, 2002) creating increasing demands on management and leadership competencies at all organisational levels. Although the need to develop leaders with adequate competencies has become obvious in recent years, there is still a significant gap between the international human resource requirements of global strategies and their realisation (Morrison, 2000; Fitzerald \& Schutte, 2010).

Management exists for the sake of the institution's results. Starting with the intended results, it has to organise the resources of the institution to attain these results. It is the organ to make the institution, whether business, church, university, hospital or community group; capable of producing results outside of itself. The centre of a modern society, economy and community is not technology. It is not information. It is not productivity. It is the managed institution as the organ of society to produce results. And management is the specific tool, the specific function, the specific instrument to make institutions capable of producing results and bringing out change. Every organisation operates on a Theory of the Business (Drucker, 1994) and strategic leadership converts it into performance (Crevani, Lindgren \& Packendorff, 2008). Its purpose is to enable an organisation to achieve its desired results in an unpredictable environment; for emergent strategy allows an organisation to be purposefully opportunistic. Emergent strategy is also the test of the Theory of the Business. Mirabeau \& Macguire (2014) posit that the failure of deliberate strategy to produce the expected results is usually aninsightful indication that Drucker's (1994) Theory of the Business needs to be thought through again so that organisations can accommodate both deliberate and emergent strategy.

But what can strategy be based on in a period of rapid change and total uncertainty, such as the world is facing at the turn of the 21st century? Are there any assumptions on which to base the strategies of a business, organisation, and nation? How can local imperatives and national imperatives be reconciled in bringing about large-scale systemic transformations? Are there any certainties? Five phenomena can be considered as certainties: (i) the collapsing birth rates in the developed world and, increasing growth rates with ever-younger populations in the developing world, (ii) shifts in the distribution of disposable income, (iii) defining performance, (iv) global competitiveness, (v) the growing incongruence between economic globalisation and political splintering (Morse et al., 2007). In South Africa, for instance, the leadership and governance of the education sector will continue to be major subject of discord - a complex problem which has already created structural mismatch in terms of building the necessary talent pool for the knowledge economy that it seeks to become. It is also certain that it has to undergo major shifts, for example, by (i) ensuring inclusive schooling for the young majority to make them fit for the contemporary knowledge economy to the continued education of highly-schooled adult knowledge workers, (ii) creating opportunities for those who suffered the uneven and skewed development as a result of colonialism and Apartheid while harmonising prospects for those who will not benefit from the economic transformation via affirmative action but yet contribute actively towards the country's global competitiveness (McGrath \& Akoojee, 2007; Allais, Marock \& Ngcwangu, 2017).

Another example that illustrates the balancing act between local and global imperatives pertains to the way the city state of Singapore has adopted a Foucauldian approach in order to develop its human resource competencies $(\mathrm{Ng}, 2011)$. The concept of 'governmentality' has been established in the management of "...men in their relation to those other things that are customs, habits, ways of acting and thinking, and so on..." (Foucault, 2000) whereby the government carefully negotiates a process of moulding citizens into a way of thinking so that it could marshal resources for the economic and survival purposes of the state, including the acceptance of foreign talents and a sense of rootedness to the country. Understanding international interaction is essential for transnational organisations to work effectively. The level of this understanding is related to the given importance and real ownership of international competencies within an organisation (Gupta \& Govindarajan, 2002). 
Recognisably, great leaders use multiple frames to see what they need to see and to craft a story about what will work. According to Bolman \& Deal (2015), there are four different frames described as: structural, human resource, political, and symbolic that can be used to frame new sets of possibilities for leaders to use in finding their bearings and choosing a course. These frames provide leaders multiple perspectives and leadership agility for the inherently messy and ambiguous situations they regularly encounter (Table 2). Thus, Bolman \& Deal (2015) uses different frames to categorise metaphors used to describe organisational perspectives, the central concepts and image of leadership that guide them as well as the basic leadership challenges that emerge thereof.

The development such a competency model requires the study of both individual competencies that comprise global leadership and a systemic framework on which the competency model can be built. Even leaders in domestic work environments are required to prepare themselves for global businesses since the characteristics of globalisation are diffusing into the domestic environment (Irving 2010; Jokinen, 2005; Kim \& McLean, 2015). Consequently, this model would warrant for the development of human resource pools and leadership competencies with differentiated capabilities (Marquardt, Berger, \& Loan, 2004). In their paper titled "The global war for talent", Beechler \& Woodward (2009) highlighted the need for the adoption of more strategic, innovative, cooperative and generative approaches, collectively described as creative 'talent solutions.' Such multi-frame thinking requires moving beyond narrow, mechanical approaches for understanding the world. It requires the practice of systemic thinking competencies to improve organisational performance: the way leaders think determines what they see, how they act, and what results they achieve.

Table 2. The Four-Frame Model for global talentship

\begin{tabular}{|c|c|c|c|c|}
\hline & \multicolumn{4}{|c|}{ Frame } \\
\hline & Structure & Human resource & Political & Symbolic \\
\hline $\begin{array}{l}\text { Metaphor for } \\
\text { organisation }\end{array}$ & Factory & Family & Jungle & Temple, theatre \\
\hline Central concepts & $\begin{array}{l}\text { Rules, roles, goals, } \\
\text { policies, technology, } \\
\text { environment }\end{array}$ & $\begin{array}{l}\text { Needs, emotions, } \\
\text { skills, } \\
\text { relationships }\end{array}$ & $\begin{array}{l}\text { Power, conflict, } \\
\text { organisational } \\
\text { politics }\end{array}$ & $\begin{array}{l}\text { Culture, meaning, } \\
\text { metaphor, ritual, } \\
\text { ceremonies, stories, heroes }\end{array}$ \\
\hline Image of leadership & Social architecture & Empowerment & $\begin{array}{l}\text { Advocacy and } \\
\text { political savvy }\end{array}$ & Inspiration, significance \\
\hline $\begin{array}{l}\text { Basic leadership } \\
\text { challenge }\end{array}$ & $\begin{array}{l}\text { Attune structure to } \\
\text { task, technology, } \\
\text { environment }\end{array}$ & $\begin{array}{l}\text { Align } \\
\text { organisation with } \\
\text { human needs and } \\
\text { talent }\end{array}$ & $\begin{array}{l}\text { Develop } \\
\text { agenda and } \\
\text { power base }\end{array}$ & $\begin{array}{l}\text { Create faith, hope, meaning } \\
\text { and belief }\end{array}$ \\
\hline
\end{tabular}

Source: Bolman \& Deal (2015)

\section{Conclusion}

The more knowledge there is, the more uncertain times seem to be. And, the future is not what it is used to be. It is from this perspective that we propose a three-tier construct of the self, others and the organisation that contemporary global leaders need to consider in tackling large-scale systemic transformation.The main managerial implication of the present work is that management leaders should be able to relate turbulence and uncertainty, arising from concatenated issues, to a wide range of organisational phenomena such as decentralisation, decision-making styles, the use of controls, norms and values, communication, technology. It is proposed that embedding business processes (management mindset) within a value-laden feedback mechanism framework (leadership mindset) would provide the crucial analytic detail to reveal otherwise elusive solutions. Moreover, by linking this framework to a model that bridges strategy and talent, it is possible to identify global pivotal leadership talent pools, and to target organisational resources toward those talent areas that have the greatest impact on strategic advantage. This is because global strategic advantage demands that organisational professionals rely increasingly on both informal meshworks that depend on shared vision and philosophy, social relationships, trust, and on organisational structures. 


\section{References}

Allais, S., Marock, C. \& Ngcwangu, S., (2017). Planning, plumbing, or posturing? Explaining the weakness of human resource development structures and policies in South Africa. Journal of Education and Work 30(1):13-25.

Amit, R. \& Schoemaker, P.J., (1993). Strategic assets and organizational rent. Strategic Management Journal 14(1):33-46.

Andriopoulos, C. \& Lowe, A., (2000). Enhancing organisational creativity: the process of perpetual challenging. Management Decision 38(10):734-742.

Arda, Ö.A., Aslan, T. \& Alpkan, L., (2016). Review of practical implications in authentic leadership studies. ProcediaSocial and Behavioral Sciences 229: 246-252.

Avolio, B.J. \& Gardner, W.L., (2005). Authentic leadership development: Getting to the root of positive forms of leadership. The Leadership Quarterly 16(3): 315-338.

Balkundi, P., Kilduff, M. \& Harrison, D.A. (2011). Centrality and charisma: comparing how leader networks and attributions affect team performance. Journal of Applied Psychology 96(6): 1209.

Ball, S. (2004). Performativities and fabrications in the education economy: towards the performative society. In: Ball S. (Ed.) The Routledge Falmer Reader in Sociology of Education. London: Routledge Falmer.

Ball, S.J. (1999). Global trends in educational reform and struggle for the soul of the teacher. Paper presented at British Educational Research Association Conference, University of Sussex, 2-5 September.

Beechler, S. \& Woodward, I.C., (2009). The global "war for talent". Journal of International Management 15(3): 273-285.

Boardman, R. \& Sasse, M.A., (2004). Stuff goes into the computer and doesn't come out: a cross-tool study of personal information management. In: Proceedings of the SIGCHI conference on Human factors in computing systems, pp. 583-590.

Bodwell, W. \& Chermack, T.J., (2010). Organizational ambidexterity: Integrating deliberate and emergent strategy with scenario planning. Technological Forecasting and Social Change 77(2): 193-202.

Bolman, L.G. \& Deal, T.E., (2015). Think - Or sink. Leader to Leader 76: 35-40.

Bond, C. \& J. O'Byrne, D.(2014). Challenges and conceptions of globalization: An investigation into models of global change and their relationship with business practice. Cross Cultural Management 21(1): 23-38.

Bono, J.E. \& Ilies, R., (2006). Charisma, positive emotions and mood contagion. The Leadership Quarterly 17(4): 317-334.

Boudreau, J.W., Ramstad, P.M. \&Dowling, P.J., (2003). Global talentship: Toward a decision science connecting talent to global strategic success. In: Advances in Global Leadership. UK: Emerald Group Publishing Limited, pp. 63-99.

Bredeson, P.V., Klar, H.W. \& Johansson, O., (2011). Context-responsive leadership: Examining superintendent leadership in context. Education Policy Analysis Archives/ArchivosAnalíticos de Políticas Educativas, 19.

Carpenter, M.A. (2002). The implications of strategy and social context for the relationship between top management team heterogeneity and firm performance. Strategic Management Journal 23(3): 275-284.

Cohen, J.F., (2001). Environmental uncertainty and managerial attitude: Effects on strategic planning, non-strategic decision-making and organisational performance. South African Journal of Business Management 32(3): 17-31.

Crevani, L., Lindgren, M. \& Packendorff, J., (2008). Leadership as a collective construction: Re-conceptualizing leadership in knowledge-intensive firms. In:24th EGOS colloquium.

Cumming, G.S. (2016). Heterarchies: reconciling networks and hierarchies. Trends in Ecology EEvolution 31(8): 622-632.

Curzer, H.J., (2002). Aristotle's painful path to virtue. Journal of the History of Philosophy 40(2): 141-162.

Daher, N., (2016). The relationships between organizational culture and organizational innovation. International Journal of Business \& Public Administration 13(2).

DeRue, D.S. \& Ashford, S.J., (2010). Who will lead and who will follow? A social process of leadership identity construction in organizations. Academy of Management Review 35(4): 627-647.

Dess, G.G. \& Lumpkin, G.T., (2005). The role of entrepreneurial orientation in stimulating effective corporate entrepreneurship. The Academy of Management Executive 19(1): 147-156.

Dhiman, S., (2017). Self-Mastery: Mastering the "Me" in Leadership. New York: Palgrave Macmillan, pp. 43-63.

DiMaggio, P., (2001). Conclusion: The futures of business organization and paradoxes of change. The twenty-firstcentury firm: Changing economic organization in international perspective, pp.210-244.

Dinh, J. E., Lord, R. G., Gardner, W. L., Meuser, J. D., Liden, R. C., Hu, J., (2014). Leadership theory and research in the new millennium: Current theoretical trends and changing perspectives. The Leadership Quarterly 25(1): 36-62.

Dinh, J.E. \& Lord, R.G., (2012). Implications of dispositional and process views of traits for individual difference research in leadership. The Leadership Quarterly 23(4): 651-669.

Drucker, P., (1994). The Theory of the Business. Harvard Business Review (September-October): 95-104.

Drucker, P.F., (2007). Management challenges for the 21 $1^{\text {st }}$ century. New York: Harper Collins.

Dunn, T.E., Lafferty, C.L. \& Alford, K.L., (2012). Global leadership: A new framework for a changing world. SAM Advanced Management Journal 77(2): 4.

Eisenhardt, K.M. \& Bhatia, M.M., (2002). Organizational complexity and computation. Companion to Organizations, 442-466.

Fairholm, M. (2000). Reclaiming Leadership in Public Administration. Public Administration Times (July): 3.

www.jbrmr.com A Journal of the Academy of Business and Retail Management (ABRM) 
Falconer, J., (2002). Emergence happens! Misguided paradigms regarding organizational change and the role of complexity and patterns in the change landscape. Emergence 4: 117-130.

Fitzgerald, S. \& Schutte, N.S., (2010). Increasing transformational leadership through enhancing self-efficacy. Journal of Management Development 29(5): 495-505.

Foucault, M., (2000). Governmentality. In: J.D. Faubion (Ed.), Michel Foucault Power Essential Works of Foucault 1954-1984, Vol. 3.London: Penguin, pp. 201-222.

Goleman, D., (2011). Emotional mastery. Leadership Excellence 28(6):12-13.

Gronn, P., (2003). Leadership: who needs it? School Leadership E Management 23(3): 267-291.

Hagen, A., Tootoonchi, A. \& Hassan, M., (2005). Integrating entrepreneurship and strategic management activities to gain wealth: CEOs' perspectives. Journal of Competitiveness Studies 13(1): 48.

Hannah, S.T., Lord, R.G. \& Pearce, C.L., (2011). Leadership and collective requisite complexity. Organizational Psychology Review 1(3): 215-238.

Hazy, J.K., (2006). Measuring leadership effectiveness in complex socio-technical systems. Emergence-MahwahLawrence Erlbaum 8(3): 58.

Hill, C.W., Jones, G.R. \& Schilling, M.A., (2014). Strategic management theory: an integrated approach. Ohio: Cengage Learning.

Hollenbeck, G.P. \& McCall, M.W., (1999). Leadership development: Contemporary practices. Evolving Practices in Human Resource Management 2: 172-200.

Hollenbeck, G.P., McCall, M.W. \& Silzer, R.F., (2006). Leadership competency models. The Leadership Quarterly 17(4): 398-413.

Horney, N., Pasmore, B. \& O'Shea, T. (2010). Leadership agility: A business imperative for a VUCA world. Human Resource Planning 33(4): 34.

Hoskisson, R.E., Covin, J., Volberda, H.W. \& Johnson, R.A., (2011). Revitalizing entrepreneurship: The search for new research opportunities. Journal of Management Studies 48(6): 1141-1168.

Hovik, S. \& Hanssen, G.S., (2015). The impact of network management and complexity on multi-level coordination. Public Administration 93(2): 506-523.

Ireland, R.D., Hitt, M.A., Camp, S.M. \& Sexton, D.L., (2001). Integrating entrepreneurship and strategic management actions to create firm wealth. The Academy of Management Executive 15(1): 49-63.

Irving, J. A., (2010). Educating Global Leaders: Exploring Intercultural Competence in Leadership Education. Journal of International Business and Cultural Studies 3 (1):1-14.

Jokinen, T., (2005). Global Leadership Competencies: A Review and Discussion. Journal of European Industrial Training 29 (3): 199-216.

Kaiser, R.B., Hogan, R. \& Craig, S.B., (2008). Leadership and the fate of organizations. American Psychologist $63(2): 96$.

Kaplan, R.S. \& Norton, D.P., (2001). The strategy-focused organization. Strategy and Leadership 29(3): 41-42.

Kauffman, S. \& Macready, W., (1995). Technological evolution and adaptive organizations: Ideas from biology may find applications in economics. Complexity 1(2): 26-43.

Khandwalla, P.N., (1972). Environment and its impact on the organization. International Studies of Management $\mathcal{E}$ Organization 2(3):297-313.

Kim, J. \& McLean, G.N., (2015). An integrative framework for global leadership competency: Levels and dimensions. Human Resource Development International 18(3): 235-258.

Knowles, R.N., (2002). Self-organizing leadership: A way of seeing what is happening in organizations and a pathway to coherence (Part II). Emergence 4(4): 86-97.

Kopmann, J., Kock, A., Killen, C.P. \& Gemünden, H.G.(2017). The role of project portfolio management in fostering both deliberate and emergent strategy. International Journal of Project Management 35(4): 557-570.

Kotter, J.P., (2008). Force for change: How leadership differs from management. New York: Simon and Schuster Publications.

Latham, J.R., (2014). Leadership for quality and innovation: Challenges, theories, and a framework for future research. Quality Management Journal 21(1): 5.

Levinsen, K. T., (2011). Fluidity in the Networked Society - Self-initiated learning as a Digital Literacy Competence. Electronic Journal of e-Learning 9(1): 52-62.

Lingard, B., Hayes, D., Mills, M. \& Christie, P., (2003). Leading Learning: making hope practical in schools. Maidenhead: Open University Press.

Lingard, B., Ladwig, J., Mills, M., (2001).The Queensland School Reform Longitudinal Study.Vols1 and 2. Brisbane: Education Queensland.

Ljungquist, U., (2014). Unbalanced dynamic capabilities as obstacles of organisational efficiency: Implementation issues in innovative technology adoption. Innovation 16(1): 82-95.

Lord, R.G., Brown, D.J., Harvey, J.L. \& Hall, R.J., (2001). Contextual constraints on prototype generation and their multilevel consequences for leadership perceptions. The Leadership Quarterly 12(3): 311-338. 
Lumpkin, G.T. \& Dess, G.G., (1996). Clarifying the entrepreneurial orientation construct and linking it to performance. Academy of Management Review 21(1): 135-172.

Marion, R. \& Uhl-Bien, M., (2002). Complexity v. transformation: The new leadership revisited. In: Managing the Complex.IV--Conference on Complex Systems and the Management of Organizations.

Marquardt, M., Berger, N. \& Loan. P., (2004). HRD in the Age of Globalization: A Practical Guide to Workplace Learning in the Third Millennium. Basic Books, New York.

McGrath, S. \& Akoojee, S., (2007). Education and skills for development in South Africa: Reflections on the accelerated and shared growth initiative for South Africa. International Journal of Educational Development 27(4): 421-434.

Mintzberg, H. \& McHugh, A., (1985). Strategy formation in an adhocracy. Administrative Science Quarterly 160-197.

Mintzberg, H. \& Waters, J.A., (1985). Of strategies, deliberate and emergent. Strategic Management Journal 6(3): 257272.

Mintzberg, H., (1973). Strategy-making in three modes. California Management Review 16(2): 44-53.

Mintzberg, H., (2017). Strategy-Making in Three Modes. In: Mackiernan, P.(Ed). Historical Evolution of Strategic Management Volumes I and II, p.403.

Mirabeau, L. \& Maguire, S., (2014). From autonomous strategic behavior to emergent strategy. Strategic Management Journal 35(8): 1202-1229.

Mobley, W.H. \& Dorfman, P.W. (2003). Advances in global leadership. In: Mobley, W.H. and Dorfman, P.W. (Eds), Advances in Global Leadership, Vol. 3, Oxford: JAI Press.

Morse, R. S., Buss, T.F. \&Kinghorn, C. M., (2007). Transforming public leadership for the 21st century. Transformational trends in Governance and Democracy Series. National Academy of Public Administration. New York: ME Sharpe Publishers Inc.

Müceldili, B., Turan, H. \& Erdil, O., (2013). The influence of authentic leadership on creativity and innovativeness. Procedia-Social and Behavioral Sciences 99: 673-681.

Müller, R. \& Turner, R., (2010). Leadership competency profiles of successful project managers. International Journal of Project Management 28(5): 437-448.

Murthy, V. \& Murthy, A., (2014). Adaptive leadership responses: Introduction to an emerging classification of zeitgeist enactments, practices and virtues for a VUCA world. World Journal of Entrepreneurship, Management and Sustainable Development 10(3): 162-176.

Ng, P.T., (2011). Singapore's response to the global war for talent: Politics and education. International Journal of Educational Development 31(3): 262-268.

Paglis, L.L. \& Green, S.G., (2002). Leadership self-efficacy and managers' motivation for leading change. Journal of Organizational Behavior 23(2): 215-235.

Pascale, R.T., Millemann, M. \& Gioja, L., (2000). Surfing the edge of chaos: The laws of nature and the new laws of business. New York: Crown business.

Pawar, B.S. \& Eastman, K.K., (1997). The nature and implications of contextual influences on transformational leadership: A conceptual examination. Academy of Management Review 22(1): 80-109.

Petkova, I., (2014). Bureaucratic versus non-bureaucratic organization: explaining form, function, and change in new forms of organizing. Management and Organizational Studies 2(1): 33.

Poocharoen, O.O. \& Ting, B., (2015). Collaboration, co-production, networks: convergence of theories. Public Management Review 17(4): 587-614.

Rego, A., Sousa, F., Marques, C. \& eCunha, M.P., (2014). Hope and positive affect mediating the authentic leadership and creativity relationship. Journal of Business Research 67(2): 200-210.

Rose, N., (1999). Powers of Freedom: reframing political thought. Cambridge: Cambridge University Press.

Ruth, D., (2006). Frameworks of managerial competence: limits, problems and suggestions. Journal of European Industrial Training 30(3): 206-226.

Sacks, R., (1997). Requisite organisation: A total system for effective managerial organisation and managerial leadership for the 21st century. Long Range Planning 30(6): 950-952.

Schatten, M., Grd, P., Konecki, M. \& Kudelić, R., (2014). Towards a formal conceptualization of organizational design techniques for large scale multi-agent systems. Procedia Technology 15: 576-585.

Senge, P.M., (2006). The Fifth Discipline: The art and practice of the learning organization. New York Broadway: Business.

Shamir, B. \& Howell, J.M., (1999). Organizational and contextual influences on the emergence and effectiveness of charismatic leadership. The Leadership Quarterly 10(2): 257-283.

Shimizu, K. \& Hitt, M.A., (2004). Strategic flexibility: Organizational preparedness to reverse ineffective strategic decisions. The Academy of Management Executive 18(4): 44-59.

Sloan, E. B., Hazucha, J. F. \& Van Katwyk, P. T., (2003). Strategic management of global leadership talent.Advances in Global Leadership 3, 235-274. doi:10.1016/S1535-1203(02)03013-7

Springer, C.G., (2007). Leadership and Ethics in Decision Making in Public Managers'. In: Morse, R.S., Buss, T.F., Kinghorn, C.M. (Eds.) Transforming Public Leadership for the 21st Century. Armonk, New York: ME Sharpe. 
Thorn, I. M. (2012). Leadership in international organizations: Global leadership competencies. The PsychologistManager Journal 15(3): 158-163.

Uhl-Bien, M. \& Marion, R., (2009). Complexity leadership in bureaucratic forms of organizing: A meso model. The Leadership Quarterly 20(4): 631-650.

Wellman, B., Salaff, J., Dimitrova, D., Garton, L., Gulia, M. \& Haythornthwaite, C., (1996). Computer networks as social networks: Collaborative work, telework, and virtual community. Annual Review of Sociology 22(1): 213238.

Wilkins, A., Ouchi, W. G., (1983). Efficient cultures: exploring the relationship between culture and organisational performance. Administrative Science Quarterly 28: 468-481.

Zhang, X. \& Zhou, J., (2014). Empowering leadership, uncertainty avoidance, trust, and employee creativity: Interaction effects and a mediating mechanism. Organizational Behavior and Human Decision Processes 124(2):150164.

Figure 1. Leading in a global context

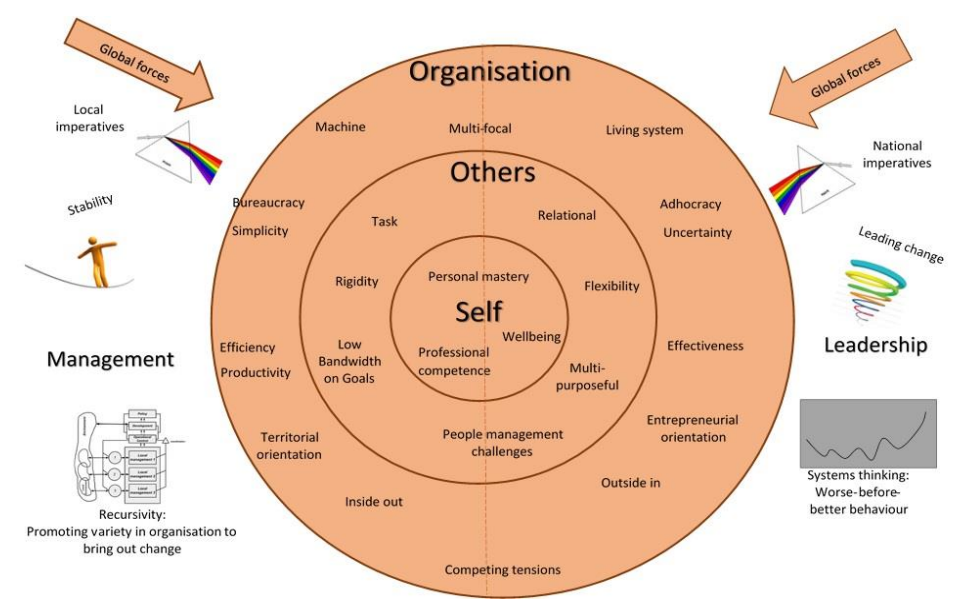

